\title{
Pancreatico-Duodenectomy with High Quality Results in a Medium Volume Centre. What are the Australian Definitions of Low Volume?
}

\author{
Ephraem Colin Lye ${ }^{1}$, Donna Gillies ${ }^{2}$ and Jon Gani ${ }^{3 *}$
}

${ }^{1}$ Surgical Registrar, John Hunter Hospital, Australia

${ }^{2}$ Surgical Audit Facilitator, John Hunter Hospital, Australia

${ }^{3}$ Visiting Surgeon, John Hunter Hospital and Lake Macquarie Private Hospital, Australia

\begin{abstract}
Introduction: Controversy about Pancreatico-Duodenectomy (PD) has persisted since it was first performed by Kausch a century ago and later popularised by Whipple. Evidence that a certain critical caseload volume is required to undertake this kind of surgery with low mortality has been the subject of some debate. Definitions of high and low volume centres and surgeons have been proposed but they differ greatly between health systems and countries.

The objective of this analysis was to determine whether it is possible to deliver pancreatico-duodenectomy at global standards in a regional city and to see if we can help define the minimum acceptable number of procedures annually compatible with providing such a service.

Methods: A ten-year retrospective study from the period of October 2002 to October 2012 was undertaken in the 1 public and 2 private hospitals in Newcastle Australia where all the PDs for a regional population of 840000 were performed.

Results: 123 pancreatico-duodenectomies were performed in this period. The mean number of operations performed each year including all hospitals combined was 12.3. This is equivalent to a medium volume centre by European definitions. The number of operations per surgeon per annum ranged from 0.2 per year to $5.8 .83 .7 \%$ of patients suffered no significant complications; 30 -day mortality was $4.1 \%$. Significant differences were found between surgeons total significant complication rates, which ranged from $8.6 \%$ to $50 \%$. 30-day mortality ranged from $0 \%$ to $50 \%$. 3 surgeons performed $>3$ operations per year. These were all designated medium volume surgeons and they performed $91 \%$ of all PDs in this series (112/123). The 3 other surgeons performed $9 \%(11 / 123)$ and were designated very low volume surgeons. One hospital performed only 4 PDs during the study period and was designated a very low volume hospital (<1case per annum). When the data from medium volume surgeons and medium volume hospitals was compared with the data from very low volume surgeons and hospitals there was a statistically significant difference in overall complication rates and mortality. Exclusion of the very low volume surgeons and the very low volume institution was associated with $1.9 \% 30$-day mortality, a $12 \%$ significant morbidity and a $31 \%$ actuarial 5 -year survival for periampullary malignancy.
\end{abstract}

Conclusion: There are both surgeon and hospital volume effects on outcome after PD. We have demonstrated that specialised Upper GI/HPB surgeons can achieve pancreatico-duodenectomy results in a medium volume centre equivalent to those achieved high volume centres.

Keywords: Pancreatico-duodenectomy; Medium volume centre; Operative outcome

\section{Introduction}

Controversy about Pancreatico-Duodenectomy (PD) has persisted since it was first performed by Kausch a century ago and later popularised by Whipple [1,2]. Long regarded as a high morbidity/ mortality procedure usually for a condition with a poor prognosis (pancreatic adenocarcinoma), its viability as a treatment option has been questioned in the past [3].

However the advances in imaging over the last 2-3 decades have improved our understanding of pancreatic neoplasia and the recognition of premalignant pancreatic lesions such as Intraduct Papillary Mucinous Tumours (IPMN) and Mucinous Cystic Neoplasm's (MCN) has increased the potential application of pancreatico-duodenectomy. Careful patient selection, a robust MDT process together with advances in peri operative care has improved the risk-benefit position for this operation and low operative mortality rates under $2 \%$ are now being reported [4-7]. However evidence of outcomes that fall below these high standards continue to be published [8-10].

Evidence that a certain critical caseload volume is required to undertake this kind of surgery with low mortality has emerged and has been the subject of some debate $[11,12]$. Birkmeyer attributed most of this effect to case volume per surgeon rather than per institution [12].

The critical number of operations per surgeon per year has been suggested; high volume has been defined as $>10-12$ cases per annum $[10,13]$, this is a caseload that is difficult to achieve in many health systems.

The critical number per hospital has also been asserted, however recommendations about the definitions of low and high volume vary greatly between counties. Medium volume hospitals in Europe would

*Corresponding author: Dr. Jon Gani, Top Floor Lake Macquarie Specialist Medical Centre, 6-8 Sydney Street, Gateshead, NSW 2290, Australia, E-mail: jonjani@mac.com

Received November 28, 2013; Accepted January 04, 2013; Published January 07,2013

Citation: Lye EC, Gillies D, Gani J (2012) Pancreatico-Duodenectomy with High Quality Results in a Medium Volume Centre. What are the Australian Definitions of Low Volume? J Integr Oncol 1:104. doi:10.4172/2329-6771.1000104

Copyright: $\odot 2012$ Lye EC, et al. This is an open-access article distributed unde the terms of the Creative Commons Attribution License, which permits unrestricted use, distribution, and reproduction in any medium, provided the original author and source are credited. 
be regarded as low volume hospitals in Asia and high volume hospital in Europe would be classified as medium volume hospitals in Asia $[6,14,15]$.

Meta-analysis of 14 studies has shown a significant association between hospital volume and survival but not surgeon volume. However the definitions of low and high volume were very discordant in this analysis, in 9 of the 14 studies low volume was defined as 3 or fewer cases per institution per year and high volume varied from 89 to 4 cases per year [16]. However even in the USA there were only 10 high volume centres performing over 25 pancreatectomies per year [17] and some low volume hospitals are still able to show satisfactory results (30 day mortality between $4-5 \%)[18,19]$. Clearly recommendations will vary for different countries and health systems.

The unique characteristics of Australia with its small population (23 million people) and its vast distances has meant that regional hospitals are required to provide tertiary services, including pancreatico-duodenectomy, to relatively small numbers of patients by global standards. We analysed our 10-year experience of pancreaticoduodenectomy in Newcastle NSW a regional centre serving a population of 840,000 people and an area of 130,000 square kilometres.

The objective of this analysis was to determine whether it is possible to deliver pancreatico-duodenectomy at global standards in a regional city and to see if we can help define the minimum acceptable number of procedures annually compatible with providing such a service.

\section{Methods}

A ten-year retrospective study from the period of October 2002 to October 2012 was undertaken. All Pancreatico-Duodenectomies (PD) performed during that period in 1 public hospital (John Hunter Hospital) and 2 private hospitals (Newcastle Private Hospital and Lake Macquarie Private Hospitals) were included in this study. We believe this to be all the pancreatico-duodenectomies performed in the region during that time.

Data was collected from the public hospital iPMS, a prospectively maintained database of GI cancer surgery in the public hospital and from individual surgeon's personal prospective databases for the private hospital patients.

6 surgeons performed the operations during the period of study. Three surgeons performed 11 procedures collectively in the 10 -year study period and were designated very low volume surgeons. 3 surgeons performed the remaining 112 procedures and were designated medium volume surgeons (individual annual mean number of procedures, 4-6). Two of the medium volume surgeons work in both public and private hospitals. All 6 surgeons in the unit regularly perform other complex abdominal procedures including Hepatectomy, Gastrectomy, Oesophagectomy, Gastric Bypass and variable amounts of Colorectal surgery. All surgeons are on a general surgical acute admitting roster at JHH. All public hospital cases were subject to a monthly peer audit process.

Over the course of the decade from 2002-2012, increasing use of the Multi-Disciplinary Team meeting was made for the pancreaticoduodenectomy patients, but not all patients were discussed.

Surgical technique was varied, consistent with the lack of evidence that any one technique is superior to another [20].

Pylorus preserving pancreatico-duodenectomy was performed in $>90 \%$ cases. Only lateral Portal Vein/Superior Mesenteric Vein excision was undertaken without interposition grafting. A variety of pancreatic anastomotic techniques were used including stented and unstented pancreatico-jejunostomy, Roux-en-Y pancreatico-jejunostomy and pancreatico-gastrostomy. Octreotide was used peri operatively in most patients. Tissue glue was used around the pancreatic anastomosis in some operations. All operations were conducted by or closely supervised by consultant Upper-Gastrointestinal/Hepato-PancreatoBiliary (UGI/HPB) surgeons.

\section{Definitions}

30 day mortality: 30 day mortality is used as recommended because it includes the great majority of surgery-related deaths and is not subject to discharge procedures [21].

Postoperative complications: Postoperative complications were recorded and classified using the Dindo-Clavien classification [22,23] Only grade 3, 4 and 5 (30 day mortality) complications were examined in this study. Grade 1(minor) and 2 (prolonged hospital stay) were not classified as significant complications. If patients experienced a grade 3 and 4 complication, only the highest grade of complication was recorded. All deaths within 30 days were recorded [24].

Resection Margins: Resection margins were determined by examining both the operation report and reviewing the histology. R0 resections were defined as negative resection margins, R1 defined as microscopic evidence of malignancy at the resection margin and R2 as presence of macroscopic evidence of tumour cells visually [25].

Survival: Actuarial 5 year survival was calculated using the KaplanMeier technique without exclusion of 30-day early postoperative deaths.

Statistical analysis was undertaken using $\mathrm{Chi}^{2}$.

\section{Results}

123 pancreatico-duodenectomies were performed in the 10-year study period. Their demographic data is shown in Table 1.

The majority of the operations $(82.9 \%, \mathrm{n}=102)$ were performed at the John Hunter Hospital ( $\mathrm{JHH})$. The 2 private hospitals performed $(17.1 \%, \mathrm{n}=21)$ of all PDs. 4 were performed at Newcastle Private Hospital (NPH) and 17 at Lake Macquarie Private Hospital (LMPH). The mean number of operations performed each year including all hospitals combined was 12.3 (Figure 1). This is equivalent to a medium volume centre by some European definitions [14].

Of the 6 surgeons who performed PD during the study period, for the purposes of this report, each surgeon is identified by a number from 1 to 6 . The number of operations per annum ranged from 0.2 per year to 5.8. One surgeon (No.6) stopped performing the operation in 2004; another surgeon (No. 5) started operating in 2008 (Table 2 and Figure 2).

\section{Significant Complications and 30-day mortality}

$83.7 \%(n=100)$ of patients suffered no significant complications. $4.1 \%(\mathrm{n}=5)$ suffered grade 3 and $8.1 \%(\mathrm{n}=10)$ suffered grade 4 complications. 30 -day mortality was $4.1 \%$ (5 patients) (Figure 3 ).

Each surgeon's complication rates were examined. Significant differences were found between surgeons total significant complication rates, which ranged from $8.6 \%$ to $50 \%$. 30-day mortality ranged from $0 \%$ to $50 \%$ (Figure 4 ).

Only 1 surgeon performed more than 5 PD per year (Surgeon 3). 
Citation: Lye EC, Gillies D, Gani J (2012) Pancreatico-Duodenectomy with High Quality Results in a Medium Volume Centre. What are the Australian Definitions of Low Volume? J Integr Oncol 1:104. doi:10.4172/2329-6771.1000104

Page 3 of 7

\section{Results $\mathrm{N}=123$}

Benign Non-neoplastic $n=11$

Gender

Age median

Pancreatitis

Pseudocyst

Fibrous stricture

Lipogranulomatosis

Benign Neo-plastic $n=4$

$$
\text { Gender }
$$

Age median

Cystadenoma

Oligocystic adenoma

\section{Pre malignant $n=13$}

Gender

Age median

IPMN

Mucinous cystadenoma

Malignant $\mathrm{n}=94$

Tubulovillous adenoma (HGD)

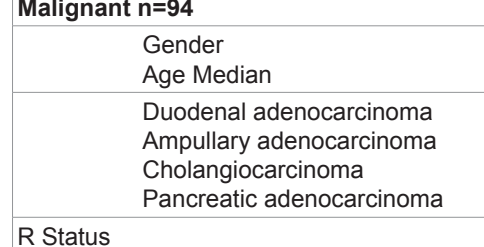

\begin{tabular}{|c|c|}
\hline $\begin{array}{l}0 \\
1 \\
2\end{array}$ & $\begin{array}{l}63(67 \%) \\
28(30 \%) \\
3(3 \%)\end{array}$ \\
\hline T Staging & $\begin{array}{l}4(4.25 \%) \\
22(23.4 \%) \\
61(64.9 \%) \\
7(7.45 \%)\end{array}$ \\
\hline N Status & $\begin{array}{l}35(37.23 \%) \\
59(62.77 \%)\end{array}$ \\
\hline Melanoma metastasis $n=1$ & M \\
\hline $\begin{array}{l}\text { Gender } \\
\text { Age median }\end{array}$ & $\begin{array}{l}1 \\
55 y r s\end{array}$ \\
\hline
\end{tabular}

Table 1: Patient demographics.

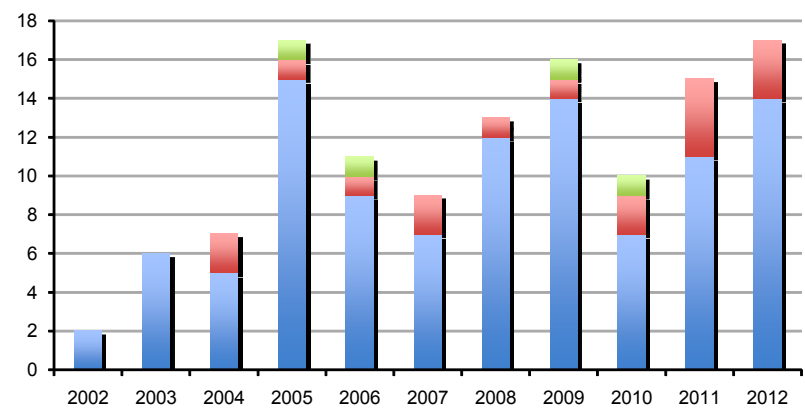

$\varpi \mathrm{JHH}=\mathrm{LMPH}=\mathrm{NPH}$

Figure 1: Number of Pancreatico-duodenectomies performed by Hospital per year.

However 3 surgeons performed $>3$ operations per year (Surgeons 1, 3 and 5). These were all designated medium volume surgeons and performed $91 \%$ of all PDs in this series (112/123). 3 other surgeons performed 9\% (11/123) and were designated very low volume surgeons.

One hospital (NPH) performed only 4 PDs during the study period and was designated a very low volume hospital ( $<$ 1case per annum) (Figure 1).

Based on the evidence that both very low volume institutions and very low volume surgeons are likely to have inferior results, all the data from the 3 very low volume surgeons and the very low volume hospital (NPH) were separated from the 3 medium volume surgeons and the 2 medium volume hospitals (JHH and LMPH). When the data from the medium volume surgeons and medium volume hospitals was compared with the data from very low volume surgeons and hospitals there were statistically significant differences in both significant complication rates and 30-day mortality rates (Table 3 ).

\begin{tabular}{|l|l|l|l|l|l|l|}
\hline Total No of PDs performed & 36 & 6 & 58 & 3 & 18 & 2 \\
\hline Surgeon ID No. & 1 & 2 & 3 & 4 & 5 & 6 \\
\hline
\end{tabular}

Table 2: Number of PDs performed by surgeon 2002-2012.

\section{No of PDs performed by each surgeon per year}

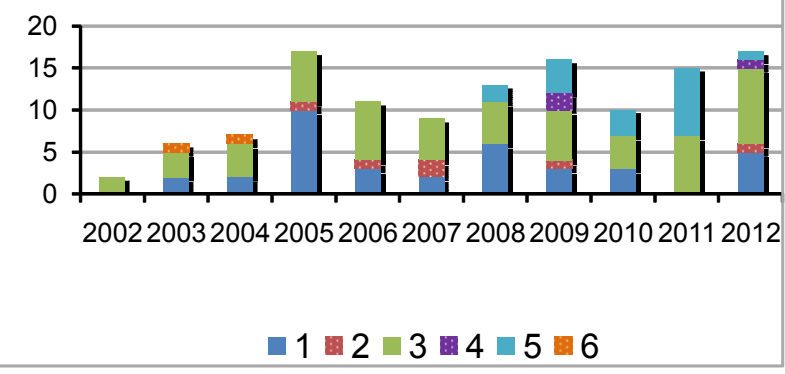

Figure 2: Number of Pancreatico-duodenectomies by surgeon per year.

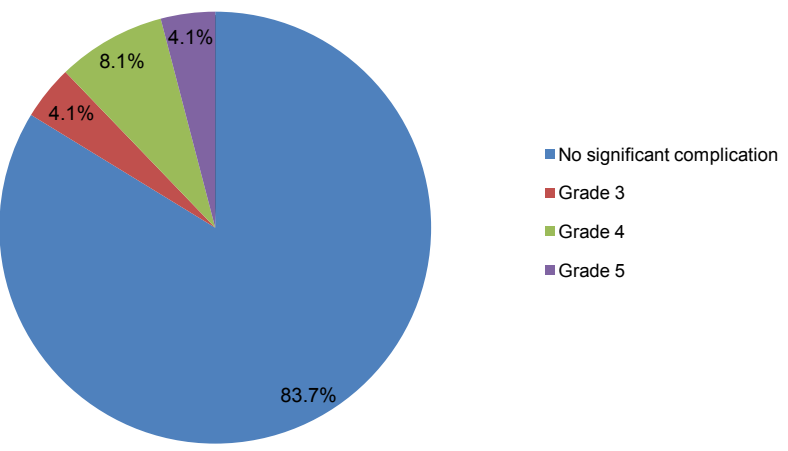

Figure 3: Complications.

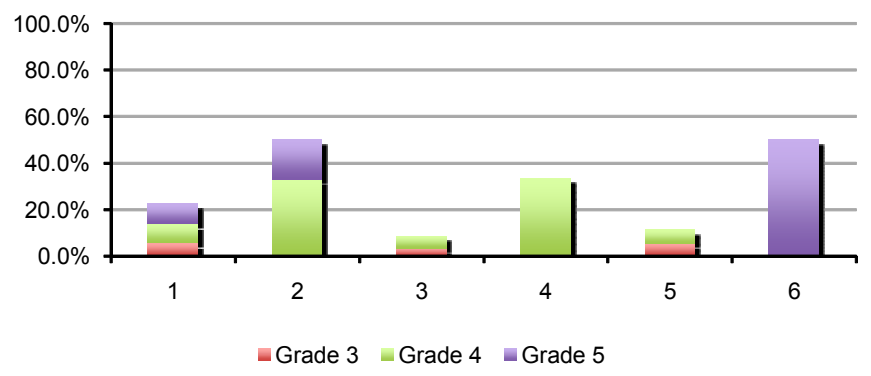

Figure 4: Percentage complication rates for individual surgeons. 
Citation: Lye EC, Gillies D, Gani J (2012) Pancreatico-Duodenectomy with High Quality Results in a Medium Volume Centre. What are the Australian Definitions of Low Volume? J Integr Oncol 1:104. doi:10.4172/2329-6771.1000104

Page 4 of 7

\begin{tabular}{|c|c|c|c|c|c|}
\hline & Very Low Volume surgeons/hospital & $\%$ & Medium Volume surgeons/hospitals & $\%$ & Chi squared \\
\hline No. of PDs performed & 15 & & 108 & & \\
\hline No. of PD patients with no significant complication & 8 & $53.3 \%$ & 95 & $88 \%$ & $P=0.003$ \\
\hline No. of PD patients $\mathbf{3 0}$ day mortality & 3 & $20 \%$ & 2 & $1.9 \%$ & $P=0.013$ \\
\hline
\end{tabular}

Table 3: Very low volume vs. medium volume outcomes.

\begin{tabular}{|c|c|c|c|c|c|c|c|c|c|c|c|c|c|}
\hline Author & $\begin{array}{l}\text { Chamber- } \\
\text { lains [28] }\end{array}$ & $\begin{array}{l}\text { Hoshal } \\
\text { [29] }\end{array}$ & $\begin{array}{l}\text { Mukherjee } \\
{[30]}\end{array}$ & Schell [31] & $\begin{array}{l}\text { Cameron } \\
{[32]}\end{array}$ & $\begin{array}{l}\text { Noda } \\
{[5]}\end{array}$ & $\begin{array}{l}\text { Suzuki } \\
{[7]}\end{array}$ & $\begin{array}{l}\text { Kim } \\
{[6]}\end{array}$ & \begin{tabular}{|l|} 
Fernán- \\
dez-del \\
Castillo \\
Castillo [3]
\end{tabular} & $\begin{array}{l}\text { Samra } \\
\text { [4] }\end{array}$ & $\begin{array}{l}\text { Speer } \\
{[33]}\end{array}$ & $\begin{array}{l}\text { This } \\
\text { series }\end{array}$ & $\begin{array}{l}\text { This series } \\
\text { Medium } \\
\text { Vol only }\end{array}$ \\
\hline Hospital & SBMC & SJMH & RLH & ML & $\mathrm{JHH}$ & & Kobe & $\begin{array}{l}\text { South } \\
\text { Korea }\end{array}$ & $\begin{array}{l}\text { Mass Gen } \\
\text { Hosp }\end{array}$ & RNSH & $\begin{array}{l}\text { Victoria } \\
\text { Australia }\end{array}$ & $\begin{array}{l}\text { Newcas- } \\
\text { tle NSW }\end{array}$ & $\begin{array}{l}\text { Newcastle } \\
\text { NSW }\end{array}$ \\
\hline $\begin{array}{l}\text { Num- } \\
\text { ber of } \\
\text { Patients }\end{array}$ & 109 & 134 & 140 & 301 & 1000 & 151 & 100 & 861 & 2050 & 178 & 87 & 123 & 108 \\
\hline Surgeon & Single & Single & Multiple & Multiple & Single & Multiple & Multiple & Multiple & Multiple & Single & Multiple & Multiple & Multiple \\
\hline$M: F$ & $1.4: 1$ & $1.2: 1$ & 1.06:1 & 1:01 & $1.2: 1$ & & $1.63: 1$ & $1: 6$ & $1.03: 1$ & & & 1.28 .1 & $1.47: 1$ \\
\hline Mean Age & 62.4 & 60 & 64 & 61 & 63.4 & & 63 & 59.9 & 62 & 67 & 68 & 63.2 & 63.4 \\
\hline Time & $\begin{array}{l}2004- \\
2009\end{array}$ & $\begin{array}{l}1985- \\
2002\end{array}$ & 1999-2006 & 1989-2003 & 1969-2003 & $2005-2010$ & 1998-2003 & $\begin{array}{l}2005- \\
2008\end{array}$ & $1940-2011$ & 2004-2010 & $\begin{array}{l}2002- \\
2003\end{array}$ & $\begin{array}{l}2002- \\
2012\end{array}$ & 2002-2012 \\
\hline $\begin{array}{l}\text { 30-Day } \\
\text { Mortality }\end{array}$ & $0.9 \%$ & $3.7 \%$ & $2.8 \%$ & $4.0 \%$ & $1.0 \%$ & $1.3 \%$ & $0 \%$ & $0.7 \%$ & $0.8 \%$ & $0.0 \%$ & $5.3 \%$ & $4.1 \%$ & $1.90 \%$ \\
\hline $\begin{array}{l}\text { Complica- } \\
\text { tions (\%) }\end{array}$ & $22.0 \%$ & $28.0 \%$ & $37.1 \%$ & $58.8 \%$ & $41.0 \%$ & $43.7 \%$ & $15.0 \%$ & & & $19.0 \%$ & & $16.3 \%$ & $12.0 \%$ \\
\hline Ref & $\begin{array}{l}\text { J Gastro- } \\
\text { intest Surg } \\
(2011) \\
15: 184- \\
190\end{array}$ & $\begin{array}{l}\text { American } \\
\text { Surgeon }\end{array}$ & EJSO & $\begin{array}{l}\text { HPB } \\
\text { Surgery }\end{array}$ & $\begin{array}{l}\text { Annuals of } \\
\text { Surgery }\end{array}$ & $\begin{array}{l}\text { Hepatogas- } \\
\text { troenterol- } \\
\text { ogy }\end{array}$ & $\begin{array}{l}\text { World J } \\
\text { Surg }\end{array}$ & $\begin{array}{l}\text { World } \\
\text { Journal } \\
\text { Gastro- } \\
\text { enterol- } \\
\text { ogy }\end{array}$ & $\begin{array}{l}\text { Surgery } \\
\text { Supp }\end{array}$ & $\begin{array}{l}\text { Hepa- } \\
\text { tobiliary } \\
\text { Pancreat } \\
\text { Dis Int }\end{array}$ & MJA & & \\
\hline & 2011 & 2004 & 2009 & 2008 & 2006 & 2012 & 2005 & 2012 & 2012 & 2012 & 2012 & & \\
\hline
\end{tabular}

Table 4: A surgeon and institution effects on outcome after PD.

\section{Survival Probability}

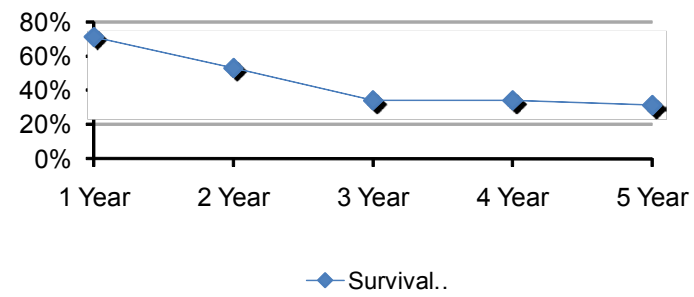

Figure 5: Kaplan-Meier Survival Probability for Malignant Cases.

\section{Resection margins}

For the patients with malignant disease, analysis of the resection margins showed that $67 \%(n=63)$ were $R 0,29.79 \%(n=28)$ were $R 1$ and $3.19 \%(n=3)$ were R2 resections. This R0 resection rate is comparable with the published results of medium volume centres but less than the high standards of high volume centres [26].

\section{Survival}

94 patients had PD for malignant disease. The survival probability on the Kaplan-Meier estimator of these patients after 5 years was $31.3 \%$ (Figure 5). There was no difference between the survival curves for patients operated on by medium volume surgeons and survival curves for all 6 surgeons combined [27-29].

This study supports the contention that there are both surgeon

\begin{tabular}{|l|l|l|l|l|l|}
\hline & $\begin{array}{l}\text { Very Low } \\
\text { Volume }\end{array}$ & $\begin{array}{l}\text { Low } \\
\text { volume }\end{array}$ & $\begin{array}{l}\text { Medium } \\
\text { Volume }\end{array}$ & $\begin{array}{l}\text { High } \\
\text { Volume }\end{array}$ & $\begin{array}{l}\text { Very High } \\
\text { Volume }\end{array}$ \\
\hline USA & & $<5$ & & $>5$ & \\
\hline Netherlands & $<5$ & $5-10$ & $11-19$ & $>20$ & \\
\hline Belgium & & $<10$ & & $>10$ & $>20$ \\
\hline Italy & $<6$ & $6-13$ & $14-51$ & $89-104$ & \\
\hline Asia & $<10$ & $10-18$ & $19-35$ & $54-111$ & 215 \\
\hline
\end{tabular}

Table 5: USA, European, Asian Definitions of Hospital Volumes.

and institution effects on outcome after PD. Exclusion of the very low volume surgeons and the very low volume institution $(\mathrm{NPH})$ was associated with a $1.9 \% 30$ day mortality, a $12 \%$ significant morbidity and a $31 \%$ actuarial 5 year survival for periampullary malignancy [3033]. This is in line with the best-published global results (Table 4).

\section{Discussion}

The results of our retrospective analysis show that even with the inclusion of the data from very low volume surgeons, the 30-day mortality rate for PD in our institutions is below the NSW average (4.1\% vs. 6.2\%) [34] and below the Victorian State average of $5.3 \%(33)$ and below the $6.3 \%$ rate of comparable medium volume European centre [14].

However we also showed that the medium volume surgeons (4-6 PDs per year) working in a tertiary regional hospital, where major resectional GI surgery is performed routinely, can perform PancreaticoDuodenectomy with results comparable to those published from global centres (30 day mortality 1.9\%) and less than that reported from high volume European centres 3.3\% [14]. This figure approaches the mortality rates reported from centres performing over 200 PDs per year [6]. 
This can also be achieved in a private hospital where similar facilities exist and where procedures of similar complexity are routinely performed and where the medical staff is the same as those working at the public hospital. Experience needs to be maintained by performing 1-2 PDs per year. This is supported by data from much larger studies that show that hospitals performing less than $1 \mathrm{PD}$ per year have increased mortality rates [35]. Surgeons performing on average less than 3 PDs per year and hospitals performing less than 1 case per year had a significantly higher complication and 30-day mortality rates.

There are some limitations to this study. This is a retrospective study, some of the data may be subject to coding inaccuracies. Some changes have been made to the process of care in the 10 years of patient accrual, which may have affected the results, including the introduction of a multidisciplinary meeting in 2006 and changes in the detail of specimen histology reporting.

The relationship between the number of operations performed annually and outcome has been examined in previous studies, most studies show that as an institution increases the volume of procedures performed, there is an inverse relationship in the 30-day mortality and morbidity [14] However the critical cut-off levels for high, medium and low volume surgeons and institutions are not universally agreed. The definition of low volume institution ranges from less than 10 to less than 19 (Table 5) $[6,14]$ The definition of what constitutes a high volume centre is also variably defined. Birkmeyer [12] defined a high volume hospital as that performing $>5$ operations per annum in the United States between 1992 and 1995. Topal [36] defined high volume as $>10$ operations per hospital per annum and $>20$ operations per hospital per annum as very high volume in Belgium between 2000 and 2004, while Balzano [15] used a range of 14-51 per annum for high volume hospitals and 89-104 per annum for very high volume hospitals in italy in 2003. Kim et al. defined very high volume as 215 per annum in South Korea [6] (Table 5).

Besides mortality improvement, high volume centres have been shown to have improved R0 resection rates [26,37]. Resection margins are important in the long-term survival of patients [38]. Rau et al. showed that cancer related death rate in $\mathrm{R} 0$ and $\mathrm{R} 1$ resection was $60 \%$ vs. $83 \%$, median tumour survival was 22 vs. 14 months and the pattern of tumour recurrence had a greater rate of regional metastases in R1 [39]. However the definition of what constitutes R1 resection is variable as there is no consensus on the definition of microscopic resection margin. In the USA, pathologists designate an R1 resection when the tumour cells are present at the resection margin whereas their European and UK counterparts define R 1 as $<1 \mathrm{~mm}$ clearance from the resection margin [25]. We have used the USA definition of R1 in this report.

Surgeon's experience and volume is an important determinant of outcome, however the infrastructure to support the postoperative period is just as important. Pecorelli et al. compared low volume surgeons to high volume surgeons in the same institution. He showed increased pancreatic fistula rates in the low volume surgeons. There was no impact on overall morbidity or mortality rates and he attributed this to the protective effect of having surgery in a large volume centre by early recognition and effective management of complications [13].

Preoperative assessment and patient selection is probably even more important in achieving good outcomes at medium volume centres. Risk stratification might prove beneficial in patient selection. Surgical Apgar scores have been used to predict peri operative mortality and morbidity [40]. It has been shown that this scoring system was a significant predictor for grade 2 or higher complications, major morbidity and pancreatic fistula but not for mortality [40]. Venket et al. have developed a novel scoring system using age, sex, tumour size, type of surgery, and preoperative serum albumin levels as predictors of 30- day mortality and that age, sex, tumour size, Charlson index, type of surgery, and preoperative serum albumin levels as predictors of 90-day mortality. Those values were used to develop a 2 integer scoring system to predict high-risk patients [41]. A predictive score to assess post-operative pancreatic fistula rate using intraoperative assessment of the pancreatic consistency and pancreatic duct diameter have been used. It showed a high-risk gland had a 25 fold increase in pancreatico-jejunostomy associated morbidity than a low risk gland [42]. Braga et al. have also used a scoring system from 0-15 to predict post-operative complications, using pancreas texture; pancreatic duct diameter, operative blood loss, and ASA score [24]. A multidisciplinary team (MDT) is important in the patient selection process and in postoperative care as Katz et al. showed an improved 5 year survival rate from $10-18 \%$ to $27 \%$ with the introduction of MDT [43].

Hence, it has been argued, using a preoperative, operative and postoperative system of assessment, together with a robust multidisciplinary team, patients that have been effectively risk assessed can be operated on safely in a medium volume institution. Those patients at higher risk can be allocated more resources peri-operatively and post-operatively. We did not employ any of these formal risk assessments in this series but preoperative anaesthetic workup and MDT discussion (after 2006) were used routinely.

Our region shares its medical specialists across the public and private hospital systems. In anaesthetics, oncology, pathology, radiology, surgery and intensive care the same staff and the same processes of care exist. Only the nursing staff vary between the hospitals themselves. This phenomenon allows us to regard the collective experience of $\mathrm{JHH}$ and LMPH as part of the same system of care. NPH was the site of only 4 operations during this 10 -year period and therefore constituted a very low volume centre (with corresponding inferior results).

The Australian geography and population distribution make it necessary for regional hospitals to provide tertiary services although the caseloads may be relatively small by some global standards. It is important, even under these circumstances, that the delivery of a high quality services is still achieved. Our results suggest that this is possible.

The critical factors in the delivery of care are believed to be; a robust multidisciplinary team discussion process for patients, a high level of anaesthetic care, effective intensive care facilities and access to these beds as well as appropriate surgical expertise and throughput.

The skills required to undertake major resectional surgery in the abdomen are not exclusive to PD and the medium volume surgeons in this analysis were all actively performing other major GI oncological procedures during the decade of this study. This crossover of skills is probably very important in maintaining the expertise required to achieve high volume results in medium volume centres, as is the presence of supporting skills in radiology, gastroenterology, anaesthetics and intensive care [44].

\section{Conclusion}

We have demonstrated that in the health system available in Australia, specialised UGI/HPB surgeons can achieve pancreaticoduodenectomy results in a medium volume centre (European definition) equivalent to those achieved in high volume centres. However surgeons should probably refer on patients if they are unable to performing $>3$ PDs per year. PD should not be performed at hospitals where less than $1 \mathrm{PD}$ is performed per year. 
Citation: Lye EC, Gillies D, Gani J (2012) Pancreatico-Duodenectomy with High Quality Results in a Medium Volume Centre. What are the Australian Definitions of Low Volume? J Integr Oncol 1:104. doi:10.4172/2329-6771.1000104

Page 6 of 7

\section{References}

1. Siegel R, Naishadham D, Jemal A (2012) Cancer statistics, 2012. CA: a cance Whipple AO, Parsons WB, Mullins CR (1935) Treatment of carcinoma of the ampulla of vater. Ann Surg 102: 763-779.

2. Kausch W (1912) Das Carcinom der Papilla duodeni und seine radikale Entfernung. Beitr Klin Chir.

3. Fernandez-Del CC, Morales-Oyarvide V, McGrath D, Wargo JA, Ferrone CR et al. (2012) Evolution of the Whipple procedure at the Massachusetts General Hospital. Surgery 152: 56-63.

4. Samra JS, Bachmann RA, Choi J, Gill A, Neale M, et al. (2011) One hundred and seventy-eight consecutive pancreatoduodenectomies without mortality: role of the multidisciplinary approach. Hepatobiliary Pancreat Dis Int 10: 415421.

5. Noda H, Kamiyama H, Kato T, Watanabe F, Kakizawa N, et al. (2012) Factors Influencing Improved Patient Outcomes after Pancreaticoduodenectomy - A Single Institute Experience of 209 Consecutive Patients in a Decade. Hepatogastroenterology.

6. Kim CG, Jo S, Kim JS (2012) Impact of surgical volume on nationwide hospital mortality after pancreaticoduodenectomy. World J Gastroenterol 18: 41754181.

7. Suzuki Y, Fujino Y, Ajiki T, Ueda T, Sakai T, et al. (2005) No mortality among 100 consecutive pancreaticoduodenectomies in a middle-volume center. World J Surg 29: 1409-1414.

8. Lampropoulos P, Vezakis A, Paschalidis N, Balitsaris E, Zizi-Sermpetzoglou A, et al. (2012) Pancreatoduodenectomy for pancreatic cancer in a low volume institution. J BUON 17: 299-303.

9. Patra DP, Basu A, De S, Vatsal S (2010) Pancreaticoduodenectomy in a government medical college-should we proceed!!! Indian J Surg 72: 381-385.

10. Kennedy TJ, Cassera MA, Wolf R, Swanstrom LL, Hansen PD (2010) Surgeon volume versus morbidity and cost in patients undergoing pancreaticoduodenectomy in an academic community medical center. J Gastrointest Surg 14: 1990-1996.

11. Lieberman MD, Kilburn H, Lindsey M, Brennan MF (1995) Relation of perioperative deaths to hospital volume among patients undergoing pancreatic resection for malignancy. Ann Surg 222: 638-645.

12. Birkmeyer JD, Siewers AE, Finlayson EV, Stukel TA, Lucas FL, et al. (2002) Hospital volume and surgical mortality in the United States. N Engl J Med 346 1128-1137.

13. Pecorelli N, Balzano G, Capretti G, Zerbi A, Di Carlo V, Braga M (2012) Effect of surgeon volume on outcome following pancreatico-duodenectomy in a highvolume hospital. J Gastrointest Surg 16: 518-523.

14. De Wilde RF, Besselink MGH, van der Tweel I, de Hingh IHJT, van Eijck CHJ, et al. (2012) Impact of nationwide centralization of pancreatico-duodenectomy on hospital mortality. Br J Surg 99: 404-410.

15. Balzano G, Zerbi A, Capretti G, Rocchetti S, Capitanio V, et al. (2008) Effect of hospital volume on outcome of pancreaticoduodenectomy in Italy. $\mathrm{Br} \mathrm{J}$ Surg 95: 357-362.

16. Gooiker GA, van Gijn W, Wouters MWJM, Post PN, van de Velde CJH, et al. (2011) Systematic review and meta-analysis of the volume-outcome relationship in pancreatic surgery. Br J Surg 98: 485-494

17. Fong YY, Gonen MM, Rubin DD, Radzyner MM, Brennan MFM (2005) Longterm survival is superior after resection for cancer in high-volume centres. Ann Surg 242: 540-547.

18. Cheng C, Duppler D, Jaremko BK (2011) Can pancreatico-duodenectomy performed at a comprehensive community cancer centre has comparable results as major tertiary centre? J Gastrointest Oncol 2: 143-150.

19. Hoem D, Viste A (2012) Improving survival following surgery for pancreatic ductal adenocarcinoma - A ten-year experience. European Journal of Surgical Oncology. Elsevier Ltd 38: 245-251.

20. Stojadinovic AA, Brooks AA, Hoos AA, Jaques DPD, Conlon KCK, Brennan MFM (2003) An evidence-based approach to the surgical management of resectable pancreatic adenocarcinoma. Journal of the American College of Surgeons 196: 11

21. Damhuis RA, Wijnhoven BP, Plaisier PW, Kirkels WJ, Kranse R, et al. (2012)
Comparison of 30-day, 90-day and in-hospital postoperative mortality for eight different cancer types. Br J Surg 99: 1149-1154.

22. Dindo D, Demartines N, Clavien PA (2004) Classification of surgica complications: a new proposal with evaluation in a cohort of 6336 patients and results of a survey. Ann Surg 240: 205-213.

23. DeOliveira MLM, Winter JMJ, Schafer MM, Cunningham SCS, Cameron JLJ, et al. (2006) Assessment of complications after pancreatic surgery: A nove grading system applied to 633 patients undergoing pancreatico-duodenectomy. Ann Surg 244: 931-939.

24. Braga M, Capretti G, Pecorelli N, Balzano G, Doglioni C, et al. (2011)A prognostic score to predict major complications after pancreaticoduodenectomy. Ann Surg 254: 702-707.

25. Verbeke CS, Menon KV (2009) Redefining resection margin status in pancreatic cancer. HPB (Oxford) 11: 282-289.

26. La Torre M, Nigri G, Ferrari L, Cosenza G, Ravaioli M, et al. (2012) Hospital volume, margin status, and long-term survival after pancreaticoduodenectomy for pancreatic adenocarcinoma. Am Surg 78: 225-229.

27. Clark W, Silva M, Donn N, Luberice K, Humphries LA, et al. (2012) Targeting early deaths following pancreaticoduodenectomy to improve survival. J Gastrointest Surg 16: 1869-1874.

28. Chamberlain RS, Tichauer M, Klaassen Z, Paragi PR (2011) Complex pancreatic surgery: safety and feasibility in the community setting. J Gastrointest Surg 15 184-190.

29. Hoshal VL Jr, Benedict MB, David LR, Kulick J (2004) Personal experience with the Whipple operation: outcomes and lessons learned. Am Surg 70: 121-125.

30. Mukherjee S, Kocher HM, Hutchins RR, Bhattacharya S, Abraham AT (2009) Impact of hospital volume on outcomes for pancreatico-duodenectomy: A single UK HPB centre experience. European Journal of Surgical Oncology (EJSO) 35: 734-738.

31. Schell MT, Barcia A, Spitzer AL, Harris HW (2008) Pancreaticoduodenectomy: volume is not associated with outcome within an academic health care system. HPB Surg 2008: 825940

32. Cameron JL, Riall TS, Coleman J, Belcher KA (2006) One thousand consecutive pancreaticoduodenectomies. Ann Surg 244: 10-15.

33. Speer AG, Thursfield VJ, Torn-Broers Y, Jefford M (2012) Pancreatic cancer: surgical management and outcomes after 6 years of follow-up. Med J Aust 196: 511-515.

34. Harris I, Madan A, Naylor J, Chong S (2012) Mortality rates after surgery in New South Wales. ANZ J Surg 82: 871-877.

35. Kotwall CA, Maxwell JG, Brinker CC, Koch GG, Covington DL (2002) National estimates of mortality rates for radical pancreaticoduodenectomy in 25,000 patients. Ann Surg Oncol 9: 847-854.

36. Topal B, Van de Sande S, Fieuws S, Penninckx F (2007) Effect of centralization of pancreaticoduodenectomy on nationwide hospital mortality and length of stay. Br J Surg 94: 1377-1381.

37. Bilimoria KY, Talamonti MS, Sener SF, Bilimoria MM, Stewart AK, et al. (2008) Effect of hospital volume on margin status after pancreaticoduodenectomy for cancer. J Am Coll Surg 207: 510-519.

38. Konstantinidis IT, Warshaw AL, Allen JN, Blaszkowsky LS, Fernandez-De Castillo C, et al. (2012) Pancreatic Ductal Adenocarcinoma: Is There a Survival Difference for R1 Resections Versus Locally Advanced Unresectable Tumors? What Is a "True" R0 Resection? Ann Surg.

39. Rau BM, Moritz K, Schuschan S, Alsfasser G, Prall F, Klar E (2012) R1 resection in pancreatic cancer has significant impact on long-term outcome in standardized pathology modified for routine use. Surgery [Internet]. Mosby 152: S103-111.

40. Assifi MM, Lindenmeyer J, Leiby BE, Grunwald Z, Rosato EL, et al. (2012) Surgical Apgar score predicts peri operative morbidity in patients undergoing pancreatico-duodenectomy at a high-volume center. J Gastrointest Surg 16 275-281.

41. Venkat $R$, Puhan MA Schulick RD, Cameron JL, Eckhauser FE, et al. (2011) Predicting the risk of perioperative mortality in patients undergoing pancreaticoduodenectomy: a novel scoring system. Arch Surg 146: 1277-1284. 
Citation: Lye EC, Gillies D, Gani J (2012) Pancreatico-Duodenectomy with High Quality Results in a Medium Volume Centre. What are the Australian Definitions of Low Volume? J Integr Oncol 1:104. doi:10.4172/2329-6771.1000104

Page 7 of 7

42. Ansorge C, Strömmer L, Andrén-Sandberg Å, Lundell L, Herrington MK, et al. (2012) Structured intraoperative assessment of pancreatic gland characteristics in predicting complications after pancreaticoduodenectomy. $\mathrm{Br} \mathrm{J}$ Surg 99 : 1076-1082.

43. Katz MH, Wang H, Fleming JB, Sun CC, Hwang RF, et al. (2009) Long- term survival after multidisciplinary management of resected pancreatic adenocarcinoma. Ann Surg Oncol 16: 836-847.

44. Joseph B, Morton JM, Hernandez-Boussard T, Rubinfeld I, Faraj C, Velanovich V (2009) Relationship Between Hospital Volume, System Clinical Resources, and Mortality in Pancreatic Resection. Journal of the American College of Surgeons 208: 520-527. 